\title{
Analisis PVS Cloud pada Database Server
}

\author{
Analysis of VPS Server on Database Server
}

\author{
A P Sujana ${ }^{1 *}$ I Hamida ${ }^{2}$ \\ 1,2)Program Studi Sistem Komputer, Fakultas Teknik dan Ilmu Komputer, Universitas Komputer Indonesia \\ Jl. Dipati Ukur No. 112 - 116, Bandung, Indonesia 40132 \\ email:aprianti.putri.sujana@email.unikom.ac.id
}

\begin{abstract}
Cloud Computing is an information technology service that can be used or accessed by customers through the Internet network. Cloud Computing is a computing/computing model, where resources such as processors / computing power, storage, networks, and software become abstract and are given as services on the network / internet using remote access patterns. To find out how effective cloud computing is, analysis is carried out on the network. That is the VPS cloud network which is analyzed using QoS (Quality of Service). QoS is defined as a mechanism or way that allows services to operate according to their respective characteristics in IP (Internet Protocol) networks. The QoS (Quality of Service) test results obtained according to TIPHON standards fall into the very good category.
\end{abstract}

Keywords - Cloud Computing, PVS Cloud, QoS(Quality of Service)

\begin{abstract}
ABSTRAK - Cloud Computing merupakan layanan teknologi informasi yang bisa dimanfaatkan atau diakses oleh pelanggannya melalui jaringan Internet. Cloud Computing adalah sebuah model komputasi / computing, dimana sumber daya seperti processor / computing power, storage, network, dan software menjadi abstrak dan diberikan sebagai layanan di jaringan / internet menggunakan pola akses remote. Untuk mengetahui seberapa efektifnya cloud computing maka dilakukan analisis pada jaringan. Yaitu jaringan VPS cloud yang dianalisis menggunakan QoS (Quality of Service). QoS didefinisikan sebagai sebuah mekanisme atau cara yang memungkinkan layanan dapat beroperasi sesuai dengan karakteristiknya masing-masing dalam jaringan IP (Internet Protocol). Hasil pengujian QoS(Quality of Service) yang diperoleh menurut standar TIPHON termasuk dalam kategori sangat bagus. Kata Kunci - Cloud Computing, PVS Cloud, QoS(Quality of Service)
\end{abstract}

\section{Pendahuluan}

Dengan memanfaatkan cloud computing maka dibuatlah VPS cloud pada database untuk menganalisis QoS(Quality of Service)[1]. Selain itu, dengan menggunakan VPS cloud penyimpanan data lebih fleksible karena dapat diatur besar kecil ukurannya. Tidak hanya itu, data yang ada pada cloud tidak mengenal waktu dan tempat karena berbasis internet, sehingga dapat diakses kapan saja dan dimana saja. QoS mengacu pada kemampuan jaringan untuk menyediakan layanan yang lebih baik pada trafik jaringan tertentu melalui teknologi yang berbeda-beda[2]. QoS menawarkan kemampuan untuk mendefinisikan atribut-atribut layanan jaringan yang disediakan, baik secara kualitatif maupun kuantitatif [3]. Hasil analisis QoS (Quality of Service), dapat dijadikan rekomendasi untuk implementasi fisik jaringan internet yang harapan kedepannya bisa menunjang penambahan layananlayanan lainnya. Pada penelitian ini mengukur layanan jaringan internet dari parameter delay/latency, jitter, packet loss dan throughput.

Server adalah sebuah sistem komputer yang menyediakan jenis layanan (services) tertentu dalam sebuah jaringan komputer. Server didukung dengan prosesor yang bersifat csalable dan RAM yang besar, juga dilengkapi dengan sistem oprasi khusus, yang disebut sebagai sistem oprasi jaringan (network operating sistem). Server juga menjalankan perangkat lunak administratif yang mengontrol akses terhadap jaringan dan sumber daya yang terdapat didalamnya, sepertihalnya berkas atau alap pencetak (printer), dan memberikan akses kepada workstation anggota jaringan[4]. 
Cloud Computing adalah sebuah model komputasi / computing, dimana sumber daya seperti processor / computing power, storage, network, dan software menjadi abstrak dan diberikan sebagai layanan di jaringan / internet menggunakan pola akses remote. Model billing dari layanan in umumnya mirip dengan modem layanan publik. Ketersediaan on-demand sesuai kebutuhkan, mudah untuk di kontrol, dinamik dan skalabilitas yang hampir tanpa limit adalah beberapa atribut penting dari cloud computing[5].

Virtual Private Server (PVS) adalah virtual machine yang dijual sebagai layanan oleh hosting provider, dalam PVS user bisa mengakses dan mengelola seluruh aspek software dari server termasuk akses administrator di sistem oprasi server sampai aplikasi yang akan di implementasikan di server tersebut. VPS dapat dibagi menjadi beberapa VM (Virtual Machines), dimana di setiap VM adalah berupa "Virtual server" yang dapat di install system operasi tersendiri. VPS terasa seperti sebuah Dedicated Server. Dibanding dengan shared hosting, menyewa VPS akan mendapatkan resource yang lebih baik sehingga tidak terganggu jika ada problem pada website yang dikelola. Selain itu VPS mendapatkan root akses sehingga lebih leluasa dalam mengkustomasi server sesuai kebutuhan.

Database adalah sebuah sistem yang di buat untuk mengorganisasi, menyimpan dan menarik data dengan mudah. Database terdiri dari kumplan data yang terorganisir untuk 1 atau lebih penggunaan, dalam bentuk digital. Atau bisa didefinisikan juga kumpulan data yang terintegrasi dan diatuar sedemikian rupa sehingga data tersebut dapat dimanipulasi dan dicari secara cepat. Database digital diatur menggunakan Database Management System (DBMS), yang menyimpan isi database, mengizinkan pembuatan dan maintenance data dan pencarian dan akses yang lain.

Quality of Service (QoS) adalah kemampuan suatu jaringan untuk menyediakan layanan baik dengan menyediakan bandwith, mengatasi jitter dan delay.. QoS sangat ditentukan oleh kualitas jaringan yang digunakan. Terdapat beberapa faktor yang dapat menurunkan nilai QoS, seperti : redaman, distorsi, dan noise. QoS didesain untuk membantu end user (client) menjadi lebih produktif dengan memastikan bahwa user mendapatkan performasi yang handal dari aplikasi-aplikasi berbasis jaringan. QoS mengacu pada kemampuan jaringan untuk menyediakan layanan yang lebih baik pada trafik jaringan tertentu melalui teknologi yang berbedabeda. QoS merupakan suatu tantangan yang besar dalam jaringan berbasis IP dan internet secara keseluruhan. Tujuan dari QoS adalah untuk memenuhi kebutuhan-kebutuhan layanan yang berbeda, yang menggunakan infrastruktur yang sama. QoS menawarkan kemampuan untuk mendefinisikan atribut-atribut layanan yang disediakan, baik secara kualitatif maupun kuantitatif. Berikut ini merupakan parameter-parameter dadi QoS :

\section{Packet Loss}

Merupakan suatu parameter yang menggambarkan suatu kondisi yang menunjukkan jumlah total paket yang hilang, dapat terjadi karena collision dan congestion pada jaringan dan hal ini berpengaruh pada semua aplikasi karena retransmisi akan mengurangi efisiensi jaringan secara keseluruhan meskipun jumlah bandwidth cukup tersedia untuk aplikasi aplikasi tersebut. Kategori packet loss ditunjukan pada tabel 1 .

Tabel 1 Kategori Packet Loss

\begin{tabular}{|c|c|c|c|}
\hline $\begin{array}{l}\text { Kategori Packet } \\
\text { Loss }\end{array}$ & $\begin{array}{l}\text { Packet } \\
(\%)\end{array}$ & Loss & Index \\
\hline Sangat bagus & 0 & & 4 \\
\hline Bagus & 3 & & 3 \\
\hline Sedang & 15 & & 3 \\
\hline Jelek & 25 & & 1 \\
\hline
\end{tabular}

(sumber : TIPHON)

Persamaan perhitungan Packet Loss :

Packet loss $=$

(paket data dikirim-paket data diterima) x 100\% paket data yang dikirim

\section{Throughput}

Throughput yaitu kecepatan (rate) transfer data efektif, yang diukur dalam bps (bit per second). Throughput adalah jumlah total kedatangan paket yang sukses yang diamati pada tujuan selama interval waktu tertentu dibagi oleh durasi interval waktu tersebut. Kategori Throughput diperlihatkan di Tabel 2.

Tabel 2 Kategori Throughput

\begin{tabular}{lll}
\hline $\begin{array}{c}\text { Kategori } \\
\text { Throughput }\end{array}$ & $\begin{array}{c}\text { Throughput } \\
\text { (bps) }\end{array}$ & Index \\
\hline Sangat bagus & 100 & 4 \\
Bagus & 75 & 3 \\
Sedang & 50 & 2 \\
Jelek & $<25$ & 1 \\
\hline
\end{tabular}

(sumber : TIPHON) 
Persamaan perhitungan Throughput :

Throughput $=\frac{\text { paket data diterima }}{\text { lama pengamatan }}$

\section{Delay (Latency)}

Delay (Latency) merupakan waktu yang dibutuhkan data untuk menempuh jarak dari asal ke tujuan. Delay dapat dipengaruhi oleh jarak, media fisik, congesti atau juga waktu proses yang lama. Pada Tabel 3 diperlihatkan kategori dari delay dan besar delay.

Tabel 3 Kategori Delay (Latency)

\begin{tabular}{lcc}
\hline $\begin{array}{l}\text { Kategori Delay } \\
\text { (Latency) }\end{array}$ & $\begin{array}{l}\text { Besaran Delay } \\
(\mathrm{sm})\end{array}$ & Index \\
\hline Sangat bagus & $<150$ & 4 \\
Bagus & $150 \mathrm{~s} / \mathrm{d} 300$ & 3 \\
Sedang & $300 \mathrm{~s} / \mathrm{d} 450$ & 2 \\
Jelek & $>450$ & 1 \\
\hline
\end{tabular}

(sumber : TIPHON)

Persamaan perhitungan Delay (Latency):

Delay $($ latency $)=\frac{\text { Paket Length }}{\text { Link Bandwith }}$

\section{Jitter atau Kedatangan Paket}

Jitter diakibatkan oleh variasi-variasi dalam panjang antrian, dalam waktu pengolahan data, dan juga dalam waktu penghimpunan ulang paket-paket diakhir perjalanan jitter. Jitter lazimnya disebut variasi delay, berhubungan erat dengan latency, yang menunjukkan banyaknya variasi delay pada transmisi data di jaringan yang diperlihatkan pada Tabel 4.

Tabel 4 Kategori Jitter

\begin{tabular}{lcr}
\hline Kategori Jitter & Jitter $(\mathrm{sm})$ & Index \\
\hline Sangat bagus & 0 & 4 \\
Bagus & $0 \mathrm{~s} / \mathrm{d} 75$ & 3 \\
Sedang & $75 \mathrm{~s} / \mathrm{d} 125$ & 2 \\
Jelek & $125 \mathrm{~s} / \mathrm{d} \mathrm{225}$ & 1 \\
\hline
\end{tabular}

(sumber : TIPHON)[3]

Persamaan perhitungan Jitter :

Jitter $=\frac{\text { Total variasi delay }}{\text { Total paket yang diterima-1 }}$

Untuk pengukuran parameter QoS, penulis menggunakan aplikasi Wireshark[6]. Wireshark adalah packet analyzer gratis dan open - Source. Tools ini seringkali digunakan untuk menemukan masalah pada jaringan, pengembangan perangkat lunak dan protokol komunikasi, dan pendidikan.
Wireshark bersifat cross - platform dan menggunakan pcap untuk meng-capture paket jaringan. Wireshark dapat berjalan pada hampir semua sistem operasi yang tersedia.[7] Wireshark merupakan salah satu aplikasi open source yang digunakan sebagai alat analisa protocol jaringan.

\section{METODE DAN BAHAN}

\section{Diagram Blok}

Pada gambar 1 berikut ini merupakan gambaran umum sistem secara keseluruhan.

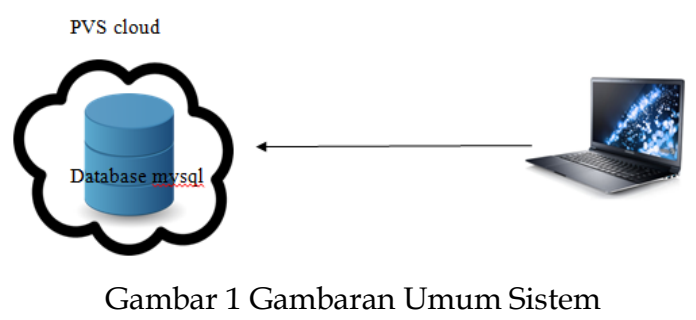

Pada Gambar 1 terdapat laptop untuk mengakses database mysql yang berada pada PVS cloud. PVS cloud ini merupakan server yang menggunakan layanan Infrastruktur As A server (IAAS). Sistem ini menggunkan pola akses remote, memungkinkan database dapat diakses dimana saja dan kapan saja mengunakan internet yang tersambung ke sistem. Sedangkan untuk perancangan sistem pada gambar 2 merupakan simulasi topologi sistem jaringan PVS Cloud dalam jaringan LAN.

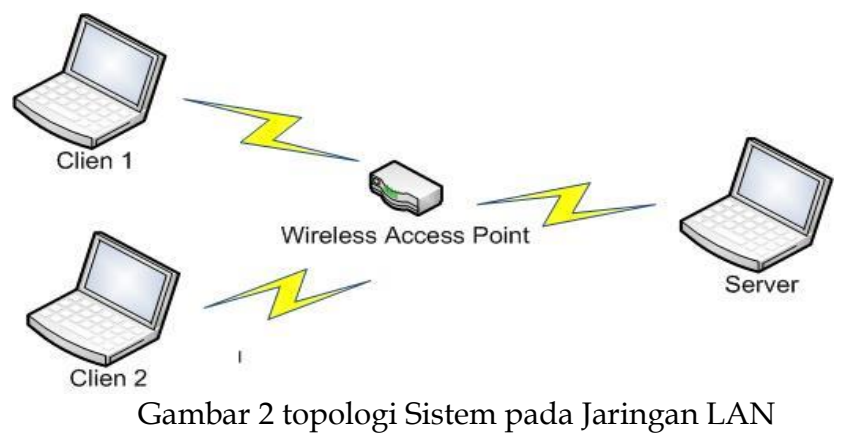

Pada gambar 2 topologi sistem dalam jaringan lokal yang menunjukan koneksi jaringan Cloud Computing yaitu digunakan satu buah laptop sebagai server dan dua buah laptop sebagai client. Laptop server akan berfungsi sebagai database server yang ada dalam jaringan VPS Cloud. Sedangkan untuk laptop client akan digunakan sebagai penguji. Komputer Cilent dan server tergabung dalam jaringan yang berbeda yang dihubungkan oleh sebuah Router yang dijadikan sebagai wireless, sehingga client dapat mengakses laptop server melalui Router tersebut. 


\section{Kebutuhan Perangkat Keras}

Kebutuhan perangkat keras menggunakan VPS Cloud dengan spesifikasi pada Tabel 5.

Tabel 5 Kebutuhan perangakat Lunak

\begin{tabular}{clc}
\hline No. & Perangkat Keras & Keterangan \\
\hline 1 & Prosessor & Intel i3 \\
2 & RAM & 4 GB \\
3 & HDD & $500 \mathrm{~GB}$ \\
\hline
\end{tabular}

\section{Kebutuhan Perangkat Lunak}

Kebutuhan perangkat lunak yang digunakan diantaranya menggunkan sitem oprasi Linux untuk dijadikan server. Selain itu digunakan juga layanan web server dan database server. Berikut ini merupakan spesifikasi perangkat lunak yang digunakan yang ada pada tabel 6 :

Tabel 6 Kebutuhan perangakat Lunak

\begin{tabular}{cll}
\hline No & Perangkat Lunak & \multicolumn{1}{c}{ Keterangan } \\
\hline 1 & Sistem Oprasi & Linux ubuntu 16.04 \\
2 & Web Server & Apache2.4.8 \\
3 & Php & Versi 5.6 dan 7.0 \\
4 & Database Server & Mysql \\
5. & Phpmyadmin & Versi 4.5.4 \\
\hline
\end{tabular}

\section{Instalasi Komponen}

Pada linux untuk menginstalasi suatu software harus menggunakan command/ perintah yang dituliskan dalam terminal. Untuk menampilkan terminal yaitu dengan meng-klik ctrl+alt+t. Sebelum meng-install layanan yang dibutuhkan oleh PVS cloud adapun command/perintah yang haru dilakukan yaitu :

Sudo apt-get update

Yaitu untuk mengapdate data yang ada pada linux. Adapun layanan yang dibutukan dalam instalasi untuk PVS cloud pada database server adalah :

1. Installasi Apache

Untuk meng-isntall web server di ubuntu 16.04 yaitu dengan mengetikan command/perintah berikut di terminal:

Sudo apt-get insta11 apache2

Tunggu proses instalasi hingga selesai, untuk mengecek apache yang telah terinstalasi yaitu dengan mengeceknya melalui browser dengan mengetikkan alamat localhostnya.

\section{Installasi PHP5.6 dan PHP7}

Untuk meng-istall PHP 5.6 dan PHP 7 yaitu dengan menuliskan perintah :

sudo apt-get instal1 php7.0 php5.6

php5.6-mysq 7 php-gettext php5.6-

mbstring php-xdebug 1ibapache2-mod-

php5.6 1ibapache2-mod-php7.0

\section{Installasi Myql Server}

Untuk meng-install Mysql server jalankan command/perintah berikut :

Sudo apt-get insta11 mysq1-server

Masukan Password untuk MySQL, setela itu dilanjutkan dengan meng-install MySQL security dengan command/perintah di bawah ini :

Mysq1_secure_installation

4. Installasi PHPmyAdmin

Untuk meng-install PHPmyAdmin jalankan command berikut :

sudo apt-get install phpmyadmin

php-mbstring php-gettext

Setelah terinstall, pada pilihan "configure phpmyadmin" pilih apache2, masukan password root sql, dan masukan password untuk phpmyadmin. Untuk mengetahui PHPmyAdmin sudah terinstall dan berjalan baik yaitu dengan men-check pada browser dengan masukan pada http://localhost/phpmyadmin.

\section{Installasi PHPmyAdmin}

Untuk meng-install PHPmyAdmin jalankan command berikut :

sudo apt-get instal1 phpmyadmin php-mbstring php-gettext

Setelah terinstall, pada pilihan "configure phpmyadmin" pilih apache2, masukan password root sql, dan masukan password untuk phpmyadmin. Untuk mengetahui PHPmyAdmin sudah terinstall dan berjalan baik yaitu dengan men-check pada browser dengan 
masukan pada

http:/ /localhost/phpmyadmin.

\section{Database yang Digunakan}

Pada analisis VPS cloud ini database yang digunakan yaitu adalah database mahasiswa dengan nama database akademik dan nama tabel terdiri dari dosen, mahasiswa, matakuliah, perkuliahan. Gambar 3 merupakan relasi Akademik yang digunakan.

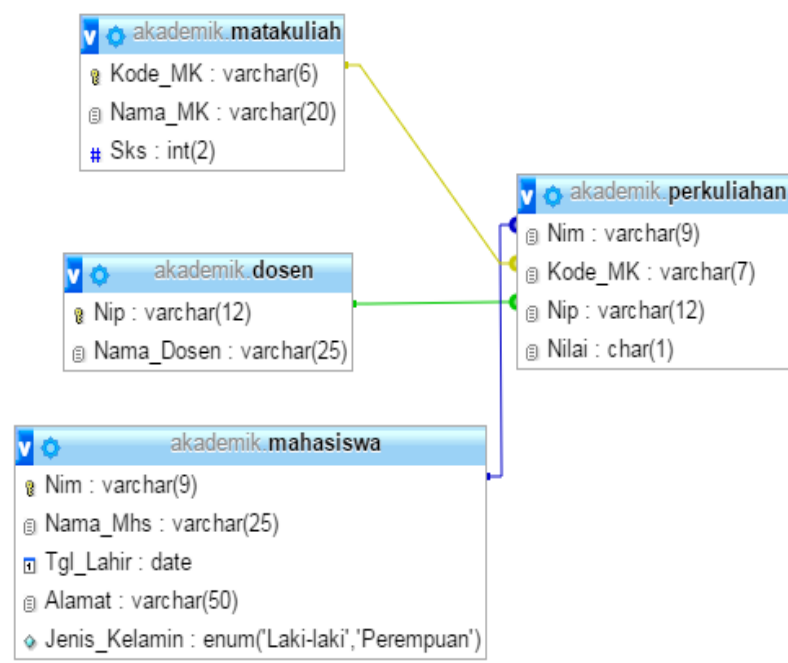

Gambar 3 Relasi Akademik

Keterangan Gambar 3 Relasi Akademik :

- Tabel dosen : Berisikan informasi dosen berupa Nip dan Nama Dosen. Yang menjadi primary key adalah Nip.

- Tabel mahasiswa : Berisikan informasi mahasiswa berupa Nim, Nama Mahasiswa, Tgl Lahir, Alamat dan Jenis Kelamin. Yang menjadi primary key adalah Nim.

- Tabel matakuliah : Berisikan informasi matakuliah yang terdiri dari Kode matakuliah, Nama matakuliah dan SKS. Yang menjadi primary key adalah Kode matakuliah.

- Tabel perkuliahan : Informasi matakuliah yang diikuti oleh siswa beserta pengajarnya dan juga nilai yang didapatkan oleh mahasiswa tsb. Tabel ini terdiri dari tiga atribut Foreign Key : Nim yang berasal dari tabel mahasiswa, Kode_MK yang berasal dari tabel matakuliah dan Nip yang berasal dari tabel dosen.

\section{HASIl DAN PEMBahasan}

Pengujian dan Analisis Throughput

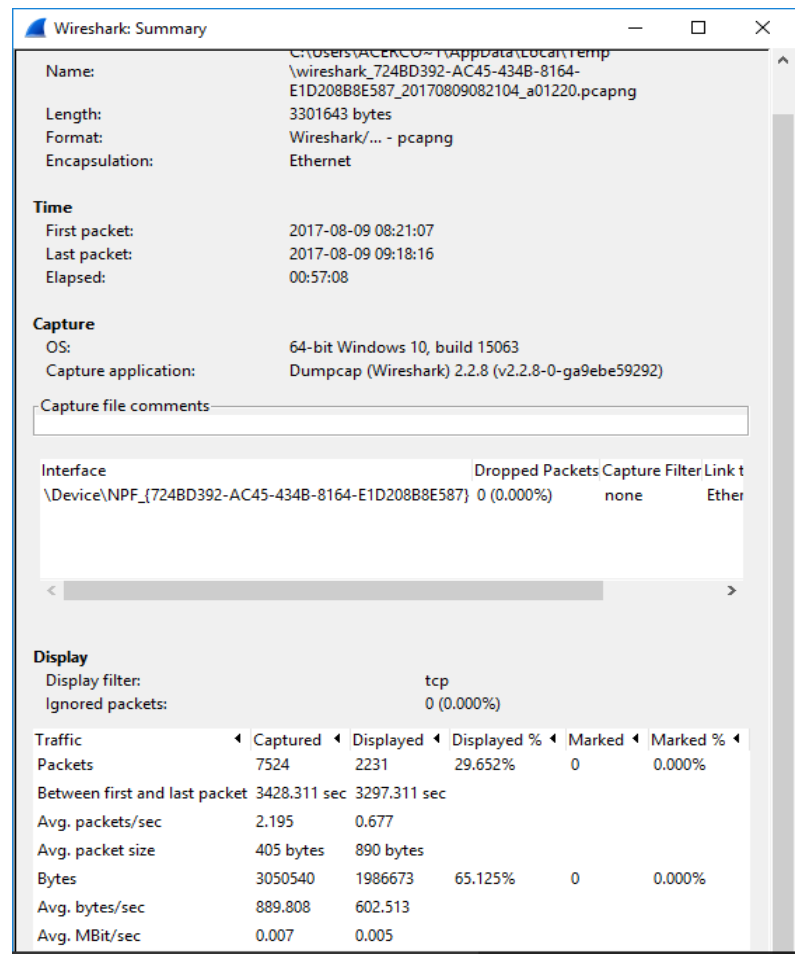

Gambar 4 Hasil Summary pada Wireshark

Pada gambar 4 merupakan hasil dari summary percobaan pertama untuk throughput yang dilakukan pada client satu. Dari hasil summary yang ada di wireshark maka didapatkan data untuk perhitungan throughput. Sesuai dengan rumus persamaan I dilakukan perhitungan throughput percobaan pertama pada client satu dengan perhitungan sebagai berikut :

Throughput $=\frac{3050540 \text { byte }}{3428,311 \mathrm{sec}}=889,808 \mathrm{byte} / \mathrm{s}$

$$
=0,00711184 \mathrm{Mbit} / \mathrm{s}
$$

Tabel 7 Perhitungan hasil Throughput pada client 1

\begin{tabular}{cccc}
\hline $\begin{array}{c}\text { Percobaan } \\
\text { ke- }\end{array}$ & $\begin{array}{c}\text { Jumlah } \\
\text { Data yang } \\
\text { Diterima } \\
\text { (byte) }\end{array}$ & $\begin{array}{c}\text { Lengalamatan } \\
\text { (sec) }\end{array}$ & $\begin{array}{c}\text { Client 1 } \\
\text { (Mbps) }\end{array}$ \\
\hline 1 & 3.050 .540 & $3.428,311$ & 0,0071 \\
2 & 604.587 & 125,005 & 0,0386 \\
3 & 581.767 & 91,989 & 0,0505 \\
4 & 597.408 & 89,826 & 0,0532 \\
5 & 579.821 & 65,749 & 0,0705 \\
6 & 617.813 & 106,357 & 0,0464 \\
7 & 606.828 & 104,697 & 0,0463 \\
8 & 586.863 & 104,351 & 0,0449 \\
9 & 600.997 & 93,257 & 0,0515 \\
10 & 95.880 & 64,622 & 0,0118 \\
\hline
\end{tabular}


Tabel 8 perhitungan hasil Throughput pada client 2

\begin{tabular}{cccc}
\hline $\begin{array}{c}\text { Jumlah } \\
\text { n ke- }\end{array}$ & $\begin{array}{c}\text { Data } \\
\text { yang } \\
\text { Diterim } \\
\text { a (byte) }\end{array}$ & $\begin{array}{c}\text { Lama } \\
\text { Pengalamata } \\
\text { n (sec) }\end{array}$ & $\begin{array}{c}\text { Clien 2 } \\
\text { (Mbps) }\end{array}$ \\
\hline 1 & 378.602 & 87,176 & 0,0347 \\
2 & 207.307 & 266,260 & 0,0062 \\
3 & 91.658 & 70,572 & 0,0103 \\
4 & 194.852 & 122,165 & 0,0127 \\
5 & 278.873 & 249,349 & 0,0089 \\
6 & 183.617 & 97,427 & 0,1507 \\
7 & 139.457 & 123,628 & 0,0092 \\
8 & 114.674 & 84,100 & 0,0109 \\
9 & 154.104 & 105,063 & 0,0117 \\
10 & 117.820 & 72,889 & 0,0129 \\
\hline
\end{tabular}

Pada tabel 7 dan 8 merupakan hasil dari perhitungan throughput yang ada pada wiresark dari client 1 dan 2 .

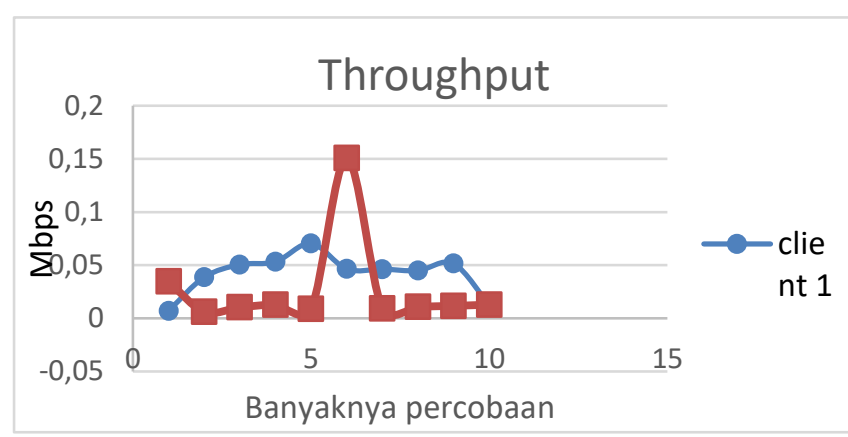

Gambar 5. Grafik Throughput

Berdasarkan Gambar 5, dapat disimpulkan bahwa nilai rata-rata throughput tertinggi pada client satu terjadi terjadi ketika percobaan ke-5 dan nilai terendah ketika percobaan ke-1 sedangkan nilai throughput tertinggi pada client dua terjadi ketika percobaan ke-6 dan nilai terendah ketika percobaan ke-2.

\section{Pengujian dan AnalisiS Paket Loss}

Paket loss merupakan suatu parameter yang menggambarkan suatu kondisi yang menunjukkan jumlah total paket yang hilang, dapat terjadi karena collision dan congestion pada jaringan. Berikut ini merupakan perhitungan dari paket loss sesuai dengan persamaan ke II dari data yang diambil di wireshark pada percobaan pertama client satu :
Tabel 9 Perhitungan Hasil Packet Loss

\begin{tabular}{|c|c|c|c|}
\hline $\begin{array}{c}\text { Percobaan } \\
\text { ke- }\end{array}$ & $\begin{array}{c}\text { Paket } \\
\text { yang } \\
\text { Dikirim }\end{array}$ & $\begin{array}{c}\text { Paket yang } \\
\text { Diterima }\end{array}$ & $\begin{array}{c}\text { Clien } 1 \\
(\%)\end{array}$ \\
\hline 1 & 7.524 & 7.524 & 0 \\
\hline 2 & 823 & 823 & 0 \\
\hline 3 & 708 & 708 & 0 \\
\hline 4 & 741 & 741 & 0 \\
\hline 5 & 660 & 660 & 0 \\
\hline 6 & 782 & 782 & 0 \\
\hline 7 & 757 & 757 & 0 \\
\hline 8 & 710 & 710 & 0 \\
\hline 9 & 749 & 749 & 0 \\
\hline 10 & 249 & 249 & 0 \\
\hline \multicolumn{4}{|c|}{ Table 10 Perhitungan Hasil Packet Loss } \\
\hline $\begin{array}{c}\text { Percobaan } \\
\text { ke- }\end{array}$ & $\begin{array}{c}\text { Paket } \\
\text { yang } \\
\text { Dikirim }\end{array}$ & $\begin{array}{c}\text { Paket yang } \\
\text { Diterima }\end{array}$ & $\begin{array}{c}\text { Clien } 1 \\
(\%)\end{array}$ \\
\hline 1 & 697 & 697 & 0 \\
\hline 2 & 1144 & 1144 & 0 \\
\hline 3 & 332 & 332 & 0 \\
\hline 4 & 633 & 633 & 0 \\
\hline 5 & 1121 & 1121 & 0 \\
\hline 6 & 588 & 588 & 0 \\
\hline 7 & 591 & 591 & 0 \\
\hline 8 & 414 & 414 & 0 \\
\hline 9 & 605 & 605 & 0 \\
\hline 10 & 410 & 410 & 0 \\
\hline
\end{tabular}

Pada tabel 9 dan 10 merupakan hasil dari perhitungan paket loss dari data yang ada pada wiresark dari client 1 dan 2 . Berdasarkan tabel 4.3 dan 4.4 nilai packet loss sesuai dengan versi TIPHON sebagai standarisasi hasil paket loss pada client 1 dan 2 dari percobaan ke-1 sampai ke-10 yaitu 0\% termasuk kategori degredasi sangat bagus.

\section{Pengujian dan Analisis Delay}

Delay adalah waktu yang di butuhkan untuk menempuh jarak dari asal ke tujuan. Berikut ini merupakan perhitungan dari persamaan III dari delay pada percobaan pertama client satu :

$$
\begin{aligned}
& \text { Delay }=\frac{3297,302}{7524}=0,43823 \mathrm{~s} \\
& =438,237 \mathrm{~ms}
\end{aligned}
$$

$$
\begin{aligned}
\text { Paket Loss }= & \frac{7524-(7524)}{7524} \times 100 \% \\
& =0 \%
\end{aligned}
$$


Pada tabel 11 dan 12 merupakan hasil dari perhitungan delay dari data yang ada pada wiresark dari client 1 dan 2 .

Tabel 11 Perhitungan Hasil Delay pada Client 1

\begin{tabular}{cccc}
\hline $\begin{array}{c}\text { Percobaan } \\
\text { ke- }\end{array}$ & $\begin{array}{c}\text { Total } \\
\text { Delay (s) }\end{array}$ & $\begin{array}{c}\text { Total } \\
\text { Paket } \\
\text { yang } \\
\text { Diterima }\end{array}$ & $\begin{array}{c}\text { Clien 1 } \\
(\mathrm{ms})\end{array}$ \\
\hline 1 & $3.297,302$ & 7.524 & 438,237 \\
2 & 108,749 & 823 & 132,137 \\
3 & 71,895 & 708 & 105,547 \\
4 & 69,121 & 741 & 93,698 \\
5 & 61,84 & 660 & 93,698 \\
6 & 76,07 & 782 & 97,288 \\
7 & 95,23 & 757 & 125,8 \\
8 & 87,271 & 710 & 122,917 \\
9 & 73,907 & 749 & 98,675 \\
10 & 55,057 & 249 & 221,115 \\
\hline
\end{tabular}

Tabel 12 Perhitungan Hasil Delay pada Client 2

\begin{tabular}{cccc}
\hline $\begin{array}{c}\text { Percobaan } \\
\text { ke- }\end{array}$ & $\begin{array}{c}\text { Total } \\
\text { Delay (s) }\end{array}$ & $\begin{array}{c}\text { Total } \\
\text { Paket yang } \\
\text { Diterima }\end{array}$ & Clien 2 (ms) \\
\hline 1 & 75,327 & 697 & 108,074 \\
2 & 207,205 & 1144 & 181,211 \\
3 & 56,833 & 332 & 171,185 \\
4 & 92,388 & 633 & 145,954 \\
5 & 119,91 & 1121 & 106,97 \\
6 & 73,63 & 588 & 125,226 \\
7 & 103,084 & 591 & 174,424 \\
8 & 66,133 & 414 & 159,694 \\
9 & 87,073 & 605 & 143,922 \\
10 & 57,768 & 410 & 140,899 \\
\hline
\end{tabular}

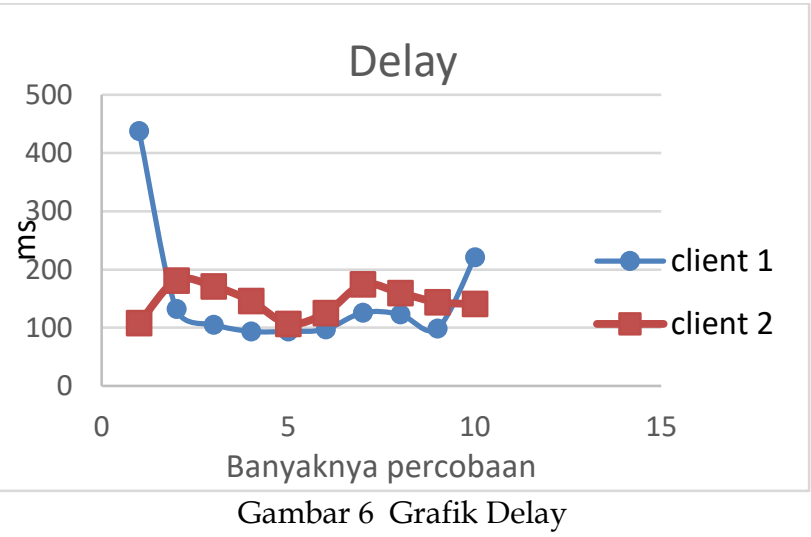

Berdasarkan Gambar 6, dapat disimpulkan ratarata delay dari client 1 dari percobaan ke-1 sampai percobaan ke-10 adalah 152,905 ms sedangkan ratarata delay dari client 2 adalah 145,75 ms. Dari hasil pengujian, berdasarkan kategori degredasi untuk
QoS versi TIPHON, nilai delay < 150 ms termasuk kedalam kategori sangat bagus sedangkan untuk delay 150 s/d 300 ms termasuk pada kategori bagus. Dari hasil pengamatan tersebut, nilai rata-rata delay yag diperoleh pada client 1 adalah 152,905 ms yang merupakan termasuk kedalam kategori bagus, sedangkan rata-rata delay pada clien 2 adalah 145,75 ms termasuk kedalam kategori sangat bagus.

\section{Pengujian dan Analisis Jitter}

Jitter diakibatkan oleh variasi-variasi dalam panjang antrian, dalam waktu pengolahan data, dan juga dalam waktu penghimpunan ulang paket-paket di akhir perjalanan jitter. Berikut ini merupakan perhitungan jitter dari persamaan IV dari pada percobaan pertama client 1 :

Jitter $=\frac{3297,302}{7524-1}=0,438296 \mathrm{~s}$

$=438,296 \mathrm{~ms}$

Tabel 13 Perhitungan Hasil Jitter

\begin{tabular}{cccc}
\hline $\begin{array}{c}\text { Percobaan } \\
\text { ke- }\end{array}$ & $\begin{array}{c}\text { Total } \\
\text { Variasi } \\
\text { Delay }\end{array}$ & $\begin{array}{c}\text { (Total } \\
\text { Paket yang } \\
\text { Diterima-1) }\end{array}$ & $\begin{array}{c}\text { Clien 1 } \\
(\mathrm{ms})\end{array}$ \\
\hline 1 & $3.297,302$ & 7.523 & 438,29 \\
2 & 108,749 & 822 & 132,29 \\
3 & 71,895 & 707 & 101,69 \\
4 & 69,121 & 740 & 98,74 \\
5 & 61,84 & 659 & 93,83 \\
6 & 76,07 & 781 & 97,4 \\
7 & 95,23 & 756 & 125,96 \\
8 & 87,271 & 709 & 123,08 \\
9 & 73,907 & 748 & 98,69 \\
10 & 55,057 & 248 & 221,97 \\
\hline
\end{tabular}

Tabel 14 Perhitungan Hasil Jitter pada Client 2

\begin{tabular}{cccc}
\hline $\begin{array}{c}\text { Percobaan } \\
\text { ke- }\end{array}$ & $\begin{array}{c}\text { Total } \\
\text { Variasi } \\
\text { Delay }\end{array}$ & $\begin{array}{c}\text { (Total Paket } \\
\text { yang } \\
\text { Diterima-1) }\end{array}$ & $\begin{array}{c}\text { Clien 2 } \\
(\mathrm{ms})\end{array}$ \\
\hline 1 & 75,327 & 696 & 108,82 \\
2 & 207,205 & 1143 & 181,13 \\
3 & 56,833 & 331 & 171,69 \\
4 & 92,388 & 632 & 145,17 \\
5 & 119,91 & 1120 & 107,06 \\
6 & 73,63 & 587 & 125,43 \\
7 & 103,084 & 590 & 174,71 \\
8 & 66,133 & 413 & 160,07 \\
9 & 87,073 & 604 & 129,25 \\
10 & 57,768 & 409 & 141,12 \\
\hline
\end{tabular}

Pada tabel 14 merupakan hasil dari perhitungan jitter dari data yang ada pada wiresark dari clien 1 dan 2 . 


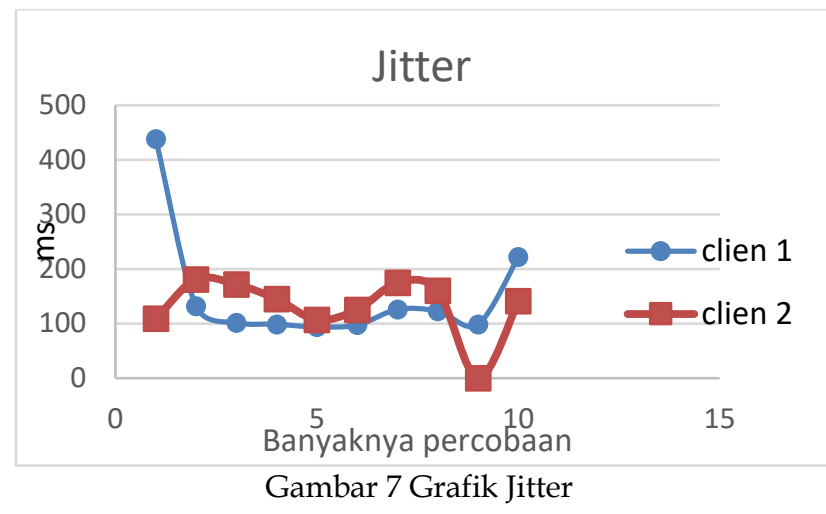

Berdasarkan Gambar 7, dapat disimpulkan bahwa nilai rata-rata jitter pada client 1 dari percobaan ke-1 sampai ke-10 adalah 153,194 ms. Sedangkan nilai rata-rata jitter tertinggi pada client dua adalah 144,445 ms. Dari hasil pengujian, berdasarkan kategori degredasi untuk QoS versi TIPHON, nilai jitter 125s/d 225 ms termasuk pada kategori jelek. Dari hasil pengamatan tersebut, nilai rata-rata jitter yang diperoleh pada client 1 dan client 2 termasuk kedalam kategori jelek.

\section{KESIMPULAN}

Dari hasil Analisis yang telah dilakukan dapat disimpulkan bahwa:

- Berdasarkan hasil pengujian, layanan VPS Cloud bisa dikatakan baik untuk digunakan oleh pelanggan, karena tidak memiliki packet loss, throughput, dan delay yang besar hanya saja masih memiliki jitter yang kurang baik. hal ini cukup baik karena dapat memberikan kesempatan pada pengguna lain untuk mengakses jaringan atau menggunakan layanan VPS cloud.

- Dengan melakukan analisis ini, dapat memberikan prioritas terhadap aplikasi-aplikasi yang kritis pada jaringan VPS cloud seperti aplikasi server dan memaksimalkan penggunaan investasi pada jaringan.

\section{UCAPAN TERIMA KASIH}

Kepada teman-teman yang telah membantu saya dalam melaksanakan penelitian ini.

\section{DAFTAR PUSTAKA}

[1] S. Danang, " Implementasi Cloud Computing untuk Optimalisasi Layanan Data Center(Studi Kasus : Upt Stmik Amikom Yogyakarta). STMIK AMIKOM, 2014

[2] A. Gani, Aplikasi Pengaruh Quality of Service (QoS) Video Conference Pada Trafik H.323 Dengan Menggunakan Metode Differentiated
Service (Diffserv), Universitas Syiah Kuala, 2010.

[3] T. Pratama, "Perbandingan Metode PCQ, SFQ, Red dan FIFO pada Mikrotik sebagai Upaya Optimalisasi Layanan Jaringan pada Fakultas Teknik Universitas Tanjungpura," Jurnal Sistem dan Teknologi Informasi (JustIN), Vol. \%1 dari \%2Vol 3, No. 1 (2015), no. Universitas Tanjungpura, 2015.

[4] Efendi. Ilham, "Apa yang Dimaksud Dengan Server" https://www.it-jurnal.com/apa-yangdi-maksud-dengan-server/ [Diakses 2017 maret 28]

[5] Purbo. Onno W. Membuat CLOUD COMPUTING SERVER menggunakan Open Source, Jakarta: Andi, 2012.

[6] U. Lamping , R. Sharpe dan E. Warnicke, "Wireshark User's Guide for Wireshark https://www.wireshark.org/download/docs/ userguide-a4.pdf. [Diakses 2017 Juli 16].

[7] Ahmad.https://09nolsembilan.blogspot.co.id/ 2015/11/pengertian-basis-data-atau-database.html [Diakses 2017 Agustus 10] 